\title{
crescimento econômico, imigração e salários reais no brasil, 1880-1937*
}

\author{
Sérgio Ricardo de Brito Gadelha \\ Analista da Secretaria do Tesouro Nacional, Mestre e Doutorando em Economia pela Universidade \\ Católica de Brasília
}

\section{RESUMO}

Este estudo demonstra que, no Brasil, 1880ᄀ 1937, mudanças na taxa de crescimento da renda real per capita sempre precederam mudanças nos níveis de imigração e de sa $\neg$ lário real, logo, é altamente provável que o crescimento da economia induziu a imigra $\neg$ ção e as variações na taxa salarial real; não o contrário. Formalmente, existiu uma relação de causalidade de Granger unidirecional do crescimento econômico, em estruturas bivariadas e multivariadas, para imigração e salário real. Não existiu causalidade, em qualquer direção, entre imigração e salário real.

Palavras-chave: Crescimento Econômico - Imigração - Salário Real — Teste de Cau $\neg$ salidade de Granger

\section{ABSTRACT}

This paper demonstrates that in Brazil, 1880ᄀ 1937, changes in the per capita real income growth rate always preceded changes in the levels of both immigration and the real wage, and so it is highly likely that it was the growth of the economy which induced the immigration and changes in the real wage, and not the other way around. Formally, there was a unidirectional Granger causality relationship from economic growth, in both a bivariate and multivariate framework, to immigration and the real wage. There was no causality, in either direction, between immigration and the real wage.

Keywords: Economic Growth - Immigration — Real Wages — Granger Causality Test

* Esse estudo faz parte de minhas contribuições à disciplina Tópicos Especiais em Crescimento Econômico do professor Steve De Castro, do departamento de Ecoᄀ nomia da Universidade de Brasília. O autor agradece ao Editor, aos pareceristas anônimos e ao professor Steve De Castro pelos valiosos comentários e sugestões. As opiniões apresentadas nesse trabalho são de exclusiva responsabilidade do autor, não expressando necessariamente a opinião da Secretaria do Tesouro Nacional. Submetido em setembro, 2008; aceito em junho, 2009. 


\section{Introdução}

A análise dos efeitos da imigração no crescimento econômico e no mercado de trabalho local é tema importante no desenho de políticas públicas, além de ser fundamental para estudiosos do crescimento econômico, tanto que Kuznets (1930) examinou as mudanças regulares na taxa de crescimento econômico de um país, as quais tinham duração entre 15 a 20 anos, denominadas balanços longos (long swings), e que geralmente terminavam em severas depressões econômicas. À luz da teoria dos Ciclos de Kuznets, Abramovitz (1961) investigou o impacto dessas mudanças em variáveis associadas ao crescimento de longo prazo, como crescimento da força de trabalho, produtividade, crescimento de cidades e acumulação de capital. Por outro lado, a característica global dessas mudanças também se manifestava sob o ritmo de fortes migrações em massa, entre as quais da Europa para o Novo Mundo, durante as expansões econômicas e mesmo em retornos migratórios líquidos, no tempo das depressões (WILLIAMSON, 1974; COLLINS, O'ROURKE e WILLIAMSON, 1997).

A relação entre crescimento econômico e imigração pode ser ilus $ᄀ$ trada pelo exemplo histórico da migração europeia em massa, na segunda metade do século XIX e início do XX, para as nações do "novo mundo" (Argentina, Austrália, Canadá, Brasil, Estados Unidos e Nova Zelândia). No Brasil, observa-se um intenso fluxo imigratório com a chegada dos italianos, em meados de 1880, tendo o Estado de São Paulo como a primeira região de atração, cujo objetivo era obter mão-deobra para a lavoura do café, em plena expansão nesse Estado, além de impulsionar o desenvolvimento industrial e o comércio.

Existe uma ampla literatura sobre esse caso (HOLLOWAY, 1972; GRAHAM, 1973; STOLKE e HALL, 1983; DEAN, 2001; LEFF, 1991, cap. 4), tanto no Brasil como no exterior. O foco principal era a microeconomia da transição da escravidão para o mercado de trabalho nas fazendas de café, em São Paulo, e a participação dos imigrantes no iní cio dos anos 1880. Esses autores perceberam a ligação entre essa parti cipação, o crescimento do PIB per capita da economia brasileira e a sua taxa salarial; mas não foi tentada uma relação quantitativa entre as variᄀ áveis, como é feita no presente estudo. 
Vários desses estudos apontam a estagnação relativa das taxas salariais agrícolas em São Paulo, especialmente entre 1884 e 1914 (veja especialᄀ mente STOLKE e HALL, 1983: 183; também HOLLOWAY, 1972). Os imigrantes dominaram o mercado de trabalho urbano na época, mas a mão-de-obra industrial era pequena em relação ao número de traba $\neg$ lhadores nas fazendas de café (DEAN, 2001). Mesmo assim, a caracterís $\neg$ tica principal dos imigrantes era a mobilidade espacial dentro do estado, passando de fazenda a fazenda, para os centros urbanos regionais, para a capital e, muitas vezes, de volta aos países de origem, sendo esse último fato ocorrido também em todos os outros países na época.

Observa-se que o papel exercido pela imigração nas economias de países originários, e anfitriões de imigrantes, tem sido um tópico de interesse no atual debate acadêmico em países desenvolvidos; todavia, poucos estudos analisam o impacto da força de trabalho imigrante nos rendimentos do mercado de trabalho e no crescimento econômico brasileiro. O problema a ser abordado neste trabalho é a direção de causalidade das três variáveis: o crescimento do PIB real per capita, a imigração per capita e a taxa salarial no Sudeste, região de maior atração da força de trabalho imigrante, durante o período de 1880-1937, caracterizado como o pico desse fluxo imigratório. Logo, este estudo deve fornecer uma contribuição para a pesquisa na área, uma vez que existe uma lacuna nessa investigação para a economia brasileira.

Os resultados obtidos evidenciam, para o período 1880-1937, a exis $\neg$ tência de relação de causalidade, no sentido de Granger, unidirecional da taxa de crescimento do PIB real per capita para a imigração per capita e para o salário real, significando que variações no crescimento econô $\neg$ mico precederam temporalmente mudanças no comportamento da força de trabalho imigrante e na trajetória dos salários reais. Em outras palavras, o crescimento econômico, provocado pela expansão cafeeira no Estado de São Paulo, incentivou a imigração para o Brasil porque havia necessidade de mão-de-obra que substituísse o trabalho escravo. Esses resultados são robustos para as versões bivariada e multivariada do teste de causalidade de Granger.

O artigo está organizado da forma a seguir. A próxima seção expliา ca o raciocínio por detrás do teste de causalidade de Granger e as apli $\neg$ cações recentes dos estudos sobre as imigrações do período pós-guerra. A terceira seção apresenta as séries temporais brasileiras das variáveis 
envolvidas na análise. A quarta descreve o tratamento econométrico, em que são apresentados os testes de raízes unitárias e o teste de causalida $\neg$ de de Granger. A quinta reporta e analisa os resultados. Finalmente, a sexta encerra o estudo.

\section{Os Estudos sobre as Imigrações do Pós-Guerra}

\subsection{Artigos que não usam causalidade}

Choques econômicos negativos podem afetar o mercado de trabalho por meio de diferentes mecanismos: um corte nos salários reais, uma elevação na taxa de desemprego ou um aumento do número de pesso $\neg$ as trabalhando no setor informal da economia. Analisando os principais determinantes da imigração para a Argentina no século XX, Solimano (2003) concluiu que a imigração contribui para o ajustamento do mer cado de trabalho local frente a choques adversos, pois o fluxo de imi $\neg$ gração em períodos de escassez de mão-de-obra e de crescimento econômico exerceu um papel importante na oferta de trabalho total.

Borjas (1994) analisou a intensidade dos fluxos migratórios que, se gundo as Nações Unidas, era estimado em torno de 60 milhões de pessoas, ou $1,2 \%$ da população mundial, que passaram a residir fora de seus locais de nascimento. Observou-se que, embora muitos imigrantes escolhessem um destino tradicional (como os Estados Unidos, o Cana dá ou a Austrália), muitos outros países estavam relativamente recebendo grandes fluxos de imigrantes. Aproximadamente $11 \%$ da população da França, $17 \%$ da população da Suíça e $9 \%$ da população do Reino Unido eram constituídos por estrangeiros. Dentre alguns resultados obtidos, Borjas (1994) concluiu que havia ausência de causalidade entre cresciᄀ mento econômico e níveis de imigração em países que adotam regras rígidas de imigração.

Friedberg e Hunt (1995) investigaram os benefícios da imigração no mercado de trabalho dos Estados Unidos e de outros países, com base no modelo de Heckscher-Ohlin e no modelo de crescimento de Solow, e os resultados encontrados indicaram que os efeitos da imigra $\neg$ ção nos rendimentos do mercado de trabalho da população nativa eram pequenos. 
Se os imigrantes e os trabalhadores nativos são substitutos perfeitos, eles competem por emprego no mesmo mercado de trabalho. Em teoria, a contribuição da imigração nos países anfitriões ocorre da seguinte maneira: (i) aumentando a força de trabalho total de um país; (ii) aumentando a oferta de trabalho em regiões com escassez de mão-deobra; e (iii) preenchendo as vagas de determinados empregos que os trabalhadores nativos evitam realizar.

\subsection{Artigos que Usam Causalidade}

Certo número de autores (FERIDUN, 2004; MORLEY, 2006) tem realizado estudos sobre o impacto da imigração no crescimento econômico e nos rendimentos do mercado de trabalho de páses desenvolvidos, utilizando o teste de causalidade de Granger. Essas investigações têm sido essenciais por quatro razões. Primeiro, uma relação de causalidade de Granger unidirecional do crescimento econômico per capita para a imigração per capita $(y \rightarrow z)$ sugere que o crescimento econômico é um dos fatores que estimularam o fluxo imigratório para um país. Por outro lado, a relação de causalidade de Granger unidirecional da imigração per capita para o crescimento econômico per capita $(z \rightarrow y)$ sugere que a imigração contribui para o crescimento da economia no período analisado. Terceiro, a relação de bicausalidade de Granger entre as variáveis analisadas $(y \leftrightarrow z)$ sugere a prevalência conjunta das duas hipóteses anteriores. Finalmente, a ausência de causalidade de Granger sugere que essas variáveis são determinadas de maneira independente uma da outra $(y \leftrightarrow z)$.

Feridun (2004) investigou a relação de causalidade entre imigração e dois indicadores macroeconômicos, PIB per capita e desemprego, usan do o teste de causalidade de Granger em dados anuais da Finlândia durante o período 1981-2001. Os resultados empíricos, obtidos a partir da estimação de um modelo vetorial autorregressivo, com mecanismo de correção de erros (VEC), evidenciaram a imigração Granger-causa do PIB per capita, indicando que o aumento da imigração contribuiu de forma positiva para o crescimento econômico daquele país.

Morley (2006) investigou a relação de causalidade entre imigração e crescimento econômico real per capita, utilizando-se de dados anuais da 
Austrália, do Canadá e dos Estados Unidos, referentes ao período de 1930 a 2002. Usando a abordagem dos modelos autorregressivos e de defasagens distribuídas (ADL) para cointegração, os resultados eviden $\neg$ ciaram uma relação de causalidade unidirecional do crescimento eco $\neg$ nômico real per capita para a imigração, e que essa relação poderia ser explicada devido ao aumento da demanda por trabalho no país anfitrião ou porque os imigrantes foram atraídos devido à perspectiva de maiores salários e elevados padrões de vida.

Apesar de utilizarem a análise de causalidade Granger em variáveis cointegradas, os resultados obtidos por Feridun (2004) e Morley (2006) são distintos em alguns aspectos. Por exemplo, a maior parte da força de trabalho imigrante analisada por Feridun (2004) é originária da Suécia e de repúblicas da ex-União Soviética, onde são exercidas atividades na construção civil e em fazendas comerciais; ao passo que, Morley (2006) não indica de maneira objetiva o nível de qualificação da mão-de-obra imigrante analisada em seu estudo. Além disso, o período por ele inves $\neg$ tigado é abrangente e as nações analisadas têm sido sujeitas a altos níveis de imigração; ao passo que, em Feridun (2004), a força de trabalho imi grante na Finlândia corresponde aproximadamente a apenas $2 \%$ da população.

Entretanto, os resultados internacionais e o exercício desenvolvido neste artigo são distintos em outros aspectos. Por exemplo, no presente estudo analisa-se um período anterior ao mencionado nos estudos de Feridun (2004) e Morley (2006), em que os fluxos migratórios foram importantes em escala internacional e, para o Brasil, de maneira espe $\neg$ cífica. O Brasil adotou uma política de incentivo à imigração no perío $\neg$ do analisado, mas nos anos posteriores apresentou controles rígidos de imigração, assim como fizeram os Estados Unidos, o Canadá e a Aus $\neg$ trália, os quais não foram inteiramente bem sucedidos (Ibidem).

\section{Dados Usados no Trabalho}

Após o Congresso Agrícola realizado em 1878, anos antes da abolição da escravatura, o governo passou a se empenhar com maior dedicação em promover a imigração para o Brasil, pois a mesma consistia em uma das únicas soluções para a escassez de mão-de-obra, uma vez que o 
tráfico de escravos africanos havia sido proibido. Parcela significante da imigração era subsidiada pelo governo e pelos senhores do café, objetivando a substituição do trabalho escravo nas suas plantações. Atraídos pelas áreas desocupadas no sul do país, os imigrantes vincularam-se à produção do trigo, do vinho e às atividades industriais. $O$ período de 1904 a 1914, início da primeira guerra mundial, é caracterizado pela chegada ao Brasil de japoneses, portugueses e espanhóis. A partir de $1919, \log$ o após o término do conflito, ocorre a chegada de imigrantes da Polônia, da Rússia e da Romênia, que imigraram por questões políticas, bem como certo número de imigrantes judeus, em meados de 1920 (LEVY, 1974). Em resumo, os imigrantes que vieram ao Brasil utilizaram recursos próprios ou foram subsidiados pelos seus países de origem, pelos fazendeiros brasileiros e pelos governos federal e estadual. A figura 1 a seguir destaca o fluxo migratório no Brasil.

\section{Figura 1 - Entradas anuais de imigrantes no Brasil}

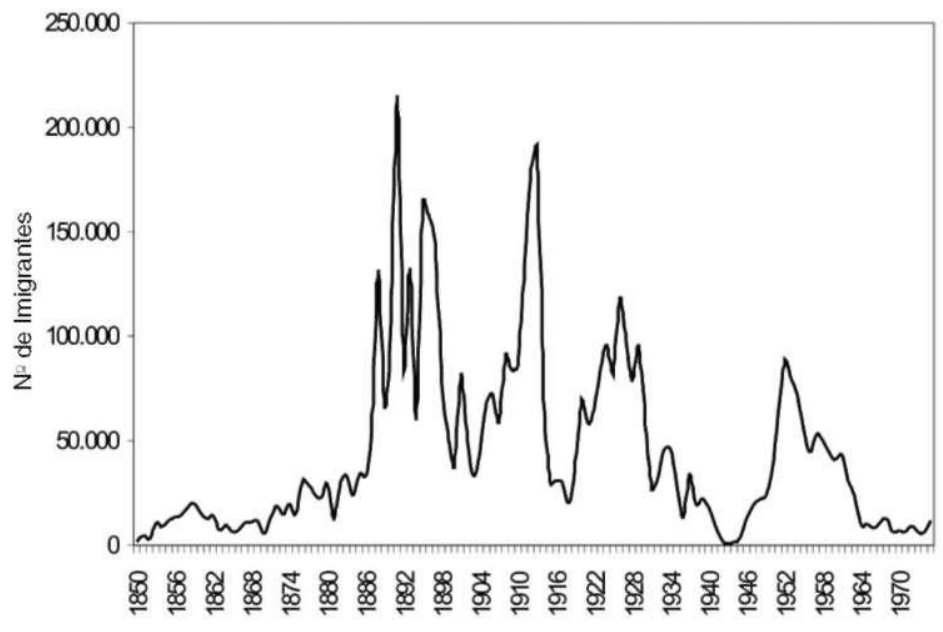

- Entrada de imigrantes

Fonte: Instituto de Pesquisa Econômica Aplicada (Ipea) e Instituto Brasileiro de Geografia e Estatística (IBGE).

Este estudo usa dados de observações anuais para o período de 1880 a 1937. Essa limitação temporal é justificada, por um lado, pela necessi- 
dade de se realizar o teste de causalidade de Granger em séries estacionárias e, por outro lado, devido à restrição dos dados sobre a variável salário real.

() crescimento económico per calpita é representado pelas taxas de crescimento anuais, compiladas a partir da série do PIB real per calpita para o periodo 1822 a 2000, apresentada em De Castro e Gonçalves $(2003)^{1}$, constantes na labela B.1 do Apêndice B. Com essa série, calcula-se $y_{t}=\left(Y_{t}-Y_{t 1}\right) / Y_{t 1}$, onde $y_{t}$ ć a taxa de crescimento do PIB real per capita, $Y_{1}$ ć o PIB real per capita no período te $Y_{i}$, co PIB real per capita no período $t-1$. A sćric resultanté ć aprescntada na labela B.2 do Apêndice B.

A força de trabalho imigranté é representada pela sćric da imigração per capita $\left(z_{t}\right)$. constrúd da a partir da relação entre número de imigrantes e a população de residentes brasileiros no período analisado, baseada nas informaçóes contidas em J eff (1991) para 1870-1872, e no sítio eletrónico do Instituto de Pesquisa Ficonomica e Aplicada (IPHA) ${ }^{2}$ para 1873-1937, constante na Tabela B.3 do Apêndice B. Na série de população de residentes brasileiros, observou-se interpolação cúbicd dos dados censitários para os anos 1890, 1900 e 1920, o que pode afetar a sćric da imigração per capita.

Quanto ao rendimento da força de trabalho, utiliza-se a sćrie do salário real $\left(x_{t}\right)$ da Região Sudeste do Brasil porque foi a destinaça principal dos imigrantes, ajustada pela praridade do poder de compra (Grä-Bretanha, 1913 = 100), e sendo obtida a partir de dados apresentados por Williamson (1998). A sćric é apresentada na Tabela B.4 do Apêndice $\mathrm{B}^{3}$.

\footnotetext{
Dados disponíveis em 〈http://www.unb.br/face/eco/steve $>$. Acessado em $30 / 10 / 2008$.

Dados disponíveis em <http://www.ipeadata.gov.br $>$. Acessado em $30 / 10 / 2008$.

Disponível em: <http://www.economics.harvard.edu/faculty/williamson/jwillia mworkingpapers $>$. Acessado em 30/10/2008.
} 


\section{Tratamento Econométrico}

Para utilizar o teste de causalidade de Granger, é necessário que as séries de tempo sejam estacionárias. Portanto, a próxima subseção iniciase com uma breve exposição dos testes dessa propriedade, antes de entrar no assunto de causalidade.

\subsection{Testes de Raízes Unitárias}

Os testes modificados de Dickey-Fuller (MADF ${ }^{\text {GLS }}$ ) e de PhillipsPerron (MPP ${ }^{\text {GLS }}$ ), propostos por Elliot, Rottemberg e Stock (1996) e Ng e Perron (2001) são aplicados para verificar a estacionariedade das séries porque superam os problemas de baixo poder estatístico e as distorções de tamanho dos testes tradicionais de Dickey-Fuller $(1979,1981)$, Said e Dickey (1984) e de Phillips-Perron (1988).

As modificações no teste-padrão de raiz unitária de Dickey e Fuller $(1979,1981)$ e de Said e Dickey (1984) fundamentam-se em dois aspectos centrais: (a) a extração de tendência em séries de tempo, usando mínimos quadrados ordinários (OLS), é ineficiente; e (b) a importância de uma seleção apropriada para a ordem de defasagem do termo aumentado permite obter-se uma melhor aproximação para o verdadeiro processo gerador de dados.

No primeiro caso, (a), Elliot, Rottemberg e Stock (1996) propõem usar mínimos quadrados generalizados (GLS) para extrair a tendência estocástica da série. Emprega-se o procedimento padrão para estimar a estatística $\mathrm{ADF}^{\mathrm{GIS}}$ como sendo a estatística $t$ para testar a hipótese nula $H_{0}: \beta_{0}=0$, indicando a presença de raiz unitária da seguinte regressão, estimada por mínimos quadrados ordinários:

$$
\Delta \tilde{y}_{t}=\beta_{0} \tilde{y}_{t-1}+\sum_{j=1}^{k} \beta_{j} \Delta \tilde{y}_{t-j}+e_{t k}
$$

contra a hipótese alternativa $H_{0}: \beta_{0}<0$, de que a série é estacionária. Em (1), $\tilde{y}_{t}$ é a série com tendência removida por mínimos quadrados generalizados, $\Delta$ é o operador de primeiras diferenças, $e_{i k}$ é o resíduo não autocorrelacionado e homoscedástico. 
Com relação ao segundo aspecto, (b), Ng e Perron (2001) demonstram que os critérios de informação de Akaike (AIC) e de Schwarz (SIC) tendem a selecionar baixos valores para a defasagem $k$, quando se tem uma grande raiz negativa (próximo a -1) no polinômio de médias móveis da série, conduzindo os testes de raízes unitárias a sérias distorções. Isso motivou o desenvolvimento do critério modificado de informação de Akaike (MAIC) para a seleção da defasagem autorregressiva, de modo a minimizar as distorções provocadas por seleção inadequada de defasagem na equação (1).

$\mathrm{Ng}$ e Perron (2001) propõem que as mesmas modificações sejam aplicadas também ao teste tradicional de Phillips e Perron (1988), originando o teste $\mathrm{MPP}^{\mathrm{aLs}}$. Por meio de simulações, Ng e Perron (2001) mostram que a aplicação conjunta de GLS para extrair a tendência de terminista e do critério de seleção de defasagens MAIC produz testes com maior poder e menores distorções de tamanho estatístico, quando comparados aos testes tradicionais ADF e PP.

\subsection{Causalidade Multivariada}

O conceito de causalidade, no sentido de Granger, está associado à ideia de precedência temporal entre variáveis. Assim, se $y$, contém

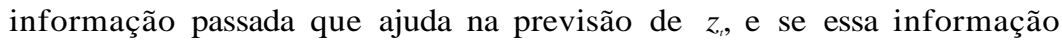
não está contida em outras séries usadas no modelo, então $y_{\text {t Granger- }}$ causa $z$ (GRANGER, 1969). A análise de causalidade multivariada inicia-se pela estimação de um modelo vetorial autoregressivo (VAR), envolvendo todas as variáveis mencionadas anteriormente. O VAR em forma reduzida de dimensão $p$ pode ser escrito com:

$$
X_{t}=A_{0}+A_{1} X_{t-1}+A_{2} X_{t-2}+\ldots+A_{p} X_{t-p}+\zeta_{t}
$$

onde, $X_{t}$ é um vetor de variáveis estacionárias, $p$ é o número de defasagens, $A_{0}$ é um vetor de interceptos, $A_{i}$ são matrizes de coeficientes e $\zeta_{t}$ é um vetor de resíduos não autocorrelacionados e homoscedásticos. No caso, o vetor $X_{t}$ contém as séries de taxa de crescimento do PIB real per capita, imigração per capita e salário real. A seleção da ordem de defasagem, $p$, é feita pelos critérios de informação de Akaike. Como a análise de causalidade não requer a estimação de parâmetros estru- 
turais, não há necessidade de se adotar alguma estratégia de identifiᄀ cação em (2).

A causalidade de Granger da variável $j$ para a variável $h$ é avaliada testando a hipótese nula de que os coeficientes da variável $j$, em todas as suas defasagens, são, simultaneamente, estatisticamente iguais a zero, na equação em que $h$ é a variável dependente. Caso a hipótese nula seja rejeitada, conclui-se que a variável $j$ Granger-causa a variável $h$.

Além da causalidade de Granger, nessa etapa duas outras técnicas econométricas serão utilizadas na análise multivariada: as funções impulso-resposta (FIR) e a análise de decomposição de variância do erro de previsão (ADV). As funções de impulso-resposta permitem avaliar o comportamento individual das variáveis do sistema, em resposta a algum choque em outra variável do modelo. Com este instrumental, analisase a sensibilidade das variáveis, por meio de simulação, a choques es $\neg$ pecíficos em um determinado período. Dessa forma, cada coeficiente demonstra a resposta de sua variável no modelo a uma inovação espe $\neg$ cífica, mantendo constantes todas as demais inovações em todos os outros períodos. Em outras palavras, a função impulso-resposta descre $\neg$ ve o caminho e as defasagens temporais necessárias para que as variáveis retornem à sua trajetória original. O efeito acumulado de uma mu dança de uma unidade em diferentes inovações sobre uma variável é dado pelo somatório dos coeficientes das funções de impulso-resposta (ENDERS, 2004, cap. 5).

A análise de decomposição de variância (ADV) é um instrumento utilizado para descrever a dinâmica do sistema na abordagem VAR. Por este método, é possível identificar a proporção da variação total de uma variável devida a cada choque individual nas $k$ variáveis componentes do modelo. A ADV fornece informações sobre a importância relativa de cada inovação sobre as variáveis do sistema (Ibidem, cap. 5).

\subsection{Causalidade Bivariada}

A análise bivariada de causalidade no sentido de Granger envolve a estimação de modelos autorregressivos de defasagens distribuídas (ADL) para pares de variáveis. A modelagem ADL é abrangente e permite capturar a dinâmica do sistema, sem incorrer no viés de omissão de defasagens relevantes. Além disso, não impõe a restrição de que todas as 
equações tenham o mesno número de defasagens em cada variável, como ocorre na estimação de VAR. Contudo, a causalidade bivariada pode ser afetada por omissão de variável no sistema. Essa limitação foi superada pelo teste multivariado de causalidade de Granger, descrito na seção 4.2. Em resumo, as duas abordagens são complementares no sentido de entender as relações de causalidade entre as três variáveis.

() teste de causalidade de Granger assume que a informação relevante para a predição das respectivas variáveis $y_{t}$ e $z_{t}$ está contida apenas nas séries de tempo sobre essas duas variáveis. Dessa forma, uma série de tempo estacionária $y_{f}$ causa, no sentido de Granger, outra série estacionária $z_{t}$, se melhores predições estatisticamente significantes de $z_{r}$ podem ser obtidas ao incluir valores defasados de $y_{t}$ aos valores defasados de $z$. Fm outras palavras, dizer que a variável $y$, Granger-causa $z_{t}$ significa que o conteúdo informacional de uma série ajuda a prever a outra. Fntretanto, outros processos podem estar causando $y$, e $z$, com defasagens distintas ou $y$, ć o resultado da antecipação da variação de $z_{t}$.

Assuma que as variáveis $z_{f}$ c $y_{t}$ scjam estacionárias em nível, isto é, $\mathrm{l}(0)$, e considere o par de modelos autorregressivos e de defasagens distribuidas (ADL):

$$
\begin{aligned}
& y_{t}-\alpha_{1}\left|\sum_{i=1}^{p} \alpha_{11}(i) y_{t-i}\right| \sum_{i=1}^{q} \alpha_{12}(i) z_{t-i} \mid \varepsilon_{y t} \\
& z_{t}=\alpha_{2}-\sum_{i=1}^{l} \alpha_{21}(i) y_{t-i}+\sum_{i=1}^{m} \alpha_{22}(i) z_{t-i}+\varepsilon_{z t}
\end{aligned}
$$

onde $\alpha_{11}(i), \alpha_{12}(i), \alpha_{21}(i), \alpha_{22}(i), \alpha_{1}, \alpha_{2}$ são parâmetros; $\alpha_{1}$ e $\alpha_{2}$ são constantes; $\varepsilon_{v t}$ e $\varepsilon_{z t}$ são erros ou processos ruídos brancos, possuindo média condicional zero e variància finita.

Nas equações (3) e (4), a hipótese nula $H_{0}: \alpha_{12}(i)=0$ significa que $z_{t}$ não Granger-causa $y_{t}$, ao passo que a hipótese alternativa $H_{A}: \alpha_{12}(i)$ $\neq 0$ significa que $z_{t}$ (Granger-causa $y_{t}$. Alternativamente, a hipótese nula $H_{0}: \alpha_{21}(i)=0$ significa que $y_{t}$ não Granger-causa $z_{i}$, ao passo que a hipótese alternativa $H_{A}: \alpha_{21}(i) \neq 0$ significa que $y_{\text {! Granger- }}$ causa $z_{1}$. Com base nessas hipóteses, são possíveis 4 resultados para cada par de variáveis. 
O teste de causalidade de Granger é sensível ao número de defasagens incluídas nos modelos ADL, influenciando na direção da causalidade. Por esse motivo, foram utilizados critérios rigorosos de seleção de defasagens, baseados nos critérios de informação de Akaike (AIC) e de Schwarz (SIC).

\section{Resultados}

\subsection{Testes de Raízes Unitárias}

Os testes modificados de Dickey-Fuller $\left(\mathrm{MADF}^{\mathrm{GLS}}\right)$ e de PhillipsPerron ( $\mathrm{MPP}^{\mathrm{GLS}}$ ), apresentados na Tabela 1 a seguir, indicam que as séries de imigração per capita $\left(z_{i}\right)$, salário real $\left(x_{t}\right)$ e taxa de crescimento do PIB real per capita (y)são estacionárias em nível, isto é, as variáveis são $\mathrm{I}(0)$.

Tabela 1 - Resultados dos testes de raiz unitária em nível, 1880-1937

\begin{tabular}{|c|c|c|c|c|}
\hline \multirow[b]{2}{*}{ VARIÁVEIS } & \multirow[b]{2}{*}{ MODELO } & \multicolumn{2}{|c|}{ MADF $^{\mathrm{GLS}}$} & \multirow[b]{2}{*}{$\mathrm{MPP}^{\mathrm{GLS}}$} \\
\hline & & ESTATÍSTICA-T & DEFASAGENS & \\
\hline$z_{i}$ & $\mathrm{C}$ & $-2,26 * *$ & 1 & $-2,11 * *$ \\
\hline$z_{i}$ & $\mathrm{C}, \mathrm{T}$ & $-2,73$ & 1 & $-2,38$ \\
\hline$x_{i}$ & $\mathrm{C}$ & $-2,03 * *$ & - & $-1,88$ \\
\hline$x_{t}$ & $\mathrm{C}, \mathrm{T}$ & $-2,34$ & - & $-2,14$ \\
\hline , & $\mathrm{C}$ & $-0,04$ & 7 & $-0,22$ \\
\hline y & $\mathrm{C}, \mathrm{T}$ & $-8,14^{*}$ & - & $-3,75^{*}$ \\
\hline
\end{tabular}

Nota: "C" significa constante. "T" significa tendência determinística. (*) significância a $1 \%$; $(* *)$ significância a 5\%. O número ótimo de defasagens segue MAIC. Contagem inicial máxima de 10 defasagens. Os valores críticos do teste $\mathrm{MADF}^{\mathrm{GLs}}$ são: (i) modelo com constante: $-2,60(1 \%)$ e $-1,94$ (5\%); (ii) modelo com constante e tendência: $-3,74(1 \%)$ e -3,16 (5\%). Os valores críticos do teste $\mathrm{MPP}^{\mathrm{GLS}}$ são: (i) modelo com constante: $-2,58(1 \%)$ e $-1,98(5 \%)$; (ii) modelo com constante e tendência: $-3,42(1 \%)$ e $-2,91(5 \%)$.

\subsection{Causalidade Multivariada}

A Tabela 2 apresenta os resultados do teste de causalidade de Granger. Observa-se uma relação de causalidade unidirecional, no sentido de 
Granger, da taxa de crescimento do PIB real per capita para a imigração per capita, ao nível de significância de $10 \%$. Em outras palavras, variações na taxa de crescimento do PIB real per capita precederam temporalmente mudanças no fluxo imigratório, sugerindo que o crescimento econômico exerceu influência sobre a imigração no período analisado. Esse resultado sugere que a imigração ocorreu em virtude da expansão da economia, principalmente no período das grandes plantações de café no Estado de São Paulo, onde se observou a substituição do trabalho escravo pela mão-de-obra imigrante, além da expansão das oportuniᄀ dades econômicas e a abundância de outros fatores, tais como: o ofere cimento de terras.

A taxa de crescimento do PIB real per capita causa, no sentido de Granger, unidirecionalmente, o salário real ao nível de significância de $1 \%$, de modo que variações no crescimento econômico precederam temporalmente variações no salário real.

A imigração per capita Granger-causa unidirecionalmente o salário real ao nível de significância de $1 \%$, mostrando que variações na imi $\neg$ gração per capita precederam temporalmente variações no salário real, sugerindo que a força de trabalho imigrante afetou os rendimentos dos trabalhadores nativos. Esse resultado sugere que o impacto da imigração sobre os salários reais é indireto, através da terceira variável, a taxa de crescimento do PIB real per capita. Entretanto, esse resultado não se manterá na análise de causalidade bivariada, a ser vista a seguir, uma vez que nessa abordagem a relação de precedência temporal é analisada em cada par das variáveis.

Tabela 2 - Resultados do teste de causalidade de Granger aplicado ao VAR

VARIÁVEIS DEPENDENTES

\begin{tabular}{c|c|c|c}
\cline { 2 - 4 } INDEPENDENTES & \multicolumn{3}{c}{$x_{*}$} \\
\hline$z_{*}$ & - & $\begin{array}{c}25,96^{*} \\
{[0,0066]}\end{array}$ & $\begin{array}{c}15,12 \\
{[0,1773]}\end{array}$ \\
\hline \multirow{2}{*}{$y_{*}$} & $\begin{array}{c}2,92 \\
{[0,9917]}\end{array}$ & $\begin{array}{c}6,03 \\
{[0,8713]}\end{array}$ \\
\hline & $\begin{array}{c}19,08 * * * \\
{[0,0597]}\end{array}$ & $\begin{array}{c}32,58^{*} \\
{[0,0006]}\end{array}$ & \\
\hline
\end{tabular}

Nota:VAR Granger Causality/Block Exogeneity Wald Tests. Observações incluídas: 47. Os valores em colchetes são os valores-p. Todos os outros valores são testes $\mathrm{x}^{2}$ da Causalidade de Granger. (*) significância a 1\%; (***) significância a 10\%. Selecionaram-se 11 defasagens ótimas no VAR irrestrito pelo critério de informação de Akaike. 
As funções de impulso-resposta mostram os efeitos de longo prazo das séries temporais, quando há um determinado choque exógeno em alguma das variáveis do modelo. De maneira específica, a técnica da função impulso-resposta é um procedimento que permite traçar os efeitos do desvio padrão de um choque relativo a uma inovação nos valores presentes e futuros das variáveis endógenas. Esse fato é transmi $\neg$ tido por uma estrutura dinâmica de um vetor autorregressivo.

A figura 2 ilustra, por consequência, as respostas produzidas pela função impulso-resposta das variáveis imigração per capita e salário real, em relação aos choques de inovação na taxa de crescimento do PIB real per capita. As linhas contínuas representam as funções impulso-resposta, enquanto as linhas pontilhadas representam os intervalos de confiança de dois desvios padrão ${ }^{4}$.

Desse modo, como na análise de causalidade multivariada, visualizase, de maneira geral, que os efeitos de choques da força de trabalho imigrante e do salário real sobre a taxa de crescimento do PIB real per capita são poucos expressivos, conforme visto na primeira fileira de gráficos. Os efeitos, caracterizados pela linha central, aproximam-se de zero. Esse resultado confirma a conclusão de que não há relação de causalidade unidirecional partindo da imigração per capita, ou do salário real, para a taxa de crescimento do PIB real per capita.

$\mathrm{Na}$ segunda fileira de gráficos, observa-se que o salário real responde de maneira significativa e positiva a inovações na taxa de crescimen $\neg$ to do PIB real per capita, exibindo uma tendência de queda em direção ao equilíbrio a partir do $5^{\circ}$ ano. Por outro lado, a análise da FIR ressalta que a resposta do salário real aos choques na imigração per capita é nulo nos três primeiros anos, tornando-se negativo no período restante.

Finalmente, a terceira fileira de gráficos mostra que a resposta da imigração per capita aos choques na taxa de crescimento do PIB real per capita é negativa em quase todo o período analisado. Além disso, a res $\neg$ posta da imigração aos choques no salário real não é expressiva, confir mando o resultado da análise de causalidade multivariada, sendo positiva em um primeiro momento, mas exibindo uma tendência de retorno à trajetória inicial a partir do segundo período.

$\mathrm{Na}$ análise das funções de impulso-resposta, foi utilizada a decomposição de Cholesky. 

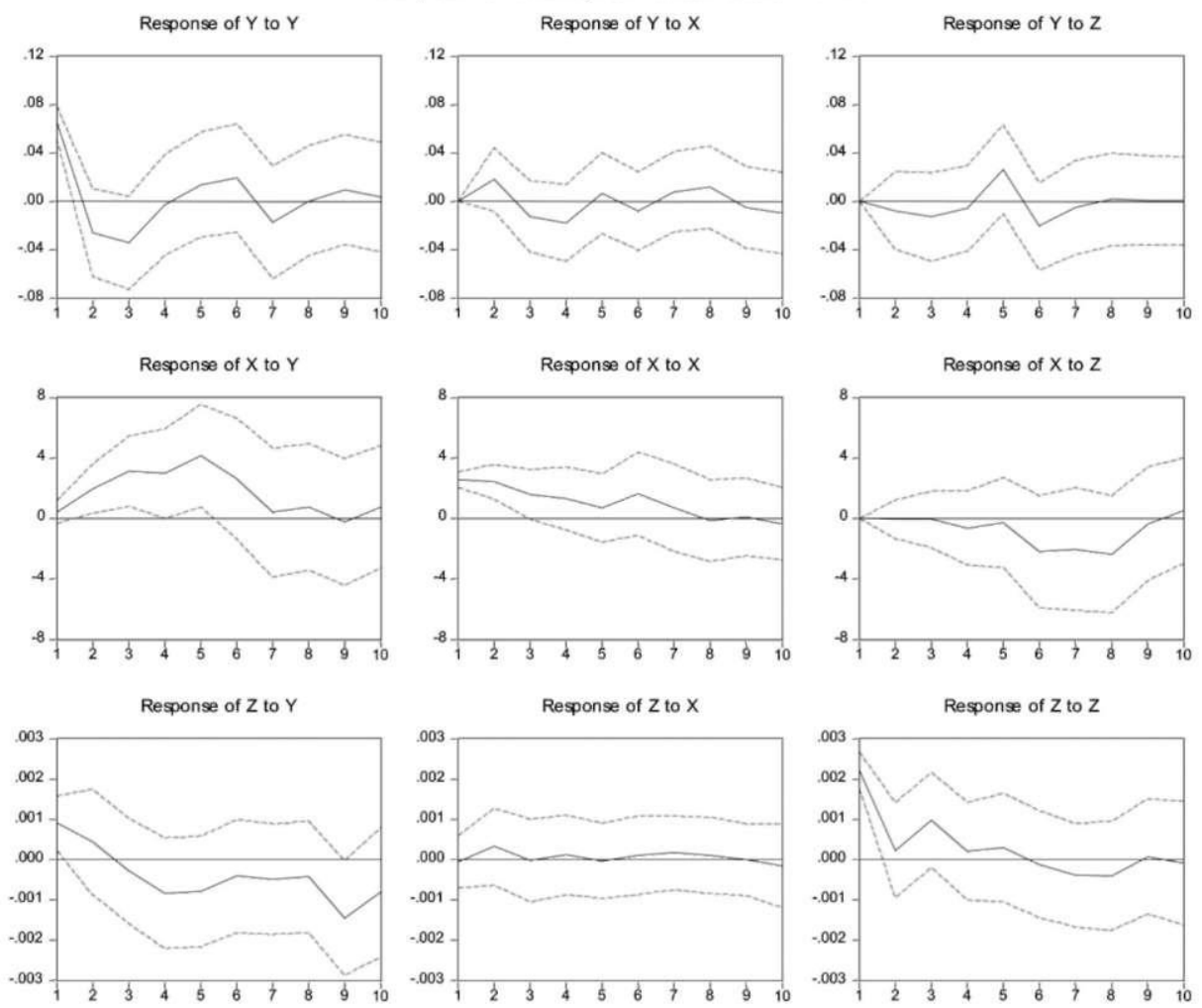

A decomposição da variância dos erros de previsão mostra a evolu ção do comportamento dinâmico apresentado pelas variáveis do sistema econômico ao longo do tempo, isto é, permite separar a variância dos erros de previsão para cada variável em componentes que podem ser atribuídos por ela própria e pelas demais variáveis endógenas, isolada $\neg$ mente, apresentando, em termos percentuais, qual o efeito que um cho $\neg$ que não antecipado sobre determinada variável tem sobre ela própria e as demais variáveis pertencentes ao sistema.

As Tabelas 3, 4 e 5 apresentam os resultados relativos à decomposição da variância dos erros de previsão para as três variáveis, onde se deterᄀ mina em cada tabela a variável atribuída a um choque não antecipado. A primeira coluna representa os períodos, no presente trabalho expres- 
sos em anos. Considera-se que um choque não antecipado sobre as variáveis analisadas perdure no máximo por 10 anos .

Na tabela 3, os resultados da decomposição da variância dos erros de previsão da taxa de crescimento do PIB real per capita mostraram que, decorridos 10 anos após um choque não antecipado sobre essa variável, aproximadamente $72,89 \%$ de seu comportamento decorrem dela própria, ao passo que aproximadamente $27,11 \%$ são atribuídos às outras variáveis: salário real $(12,57 \%)$ e imigração per capita $(14,54 \%)$.

Tabela 3 - Resultado da decomposição da variância da taxa de crescimento do PIB real per capita (y)

\begin{tabular}{c|c|c|c|c}
\multicolumn{1}{c}{ PERÍODO } & \multicolumn{1}{c}{ S.E. } & \multicolumn{1}{c}{$\mathrm{x}$} & $\mathrm{z}$ \\
\hline 1 & 0,0653 & 100,00 & 0,00 & 0,00 \\
\hline 2 & 0,0730 & 92,81 & 6,09 & 1,10 \\
\hline 3 & 0,8262 & 89,61 & 7,07 & 3,32 \\
\hline 4 & 0,0847 & 85,28 & 11,10 & 3,62 \\
\hline 5 & 0,0901 & 77,77 & 10,40 & 11,83 \\
\hline 7 & 0,0948 & 74,48 & 10,11 & 15,41 \\
\hline 8 & 0,0968 & 74,56 & 10,37 & 15,07 \\
\hline 9 & 0,0975 & 73,48 & 11,64 & 14,88 \\
\hline 10 & 0,0981 & 73,54 & 11,76 & 14,70 \\
\hline
\end{tabular}

Nota:"S.E" significa erro padrão.

Em relação ao salário real, Tabela 4, grande parte de seu próprio erro de previsão é explicada pela taxa de crescimento do PIB real per capita, cerca de $57,20 \%$, decorridos 10 anos após um choque inicial não ante cipado. Em torno de $24,32 \%$ referem-se ao próprio salário real, ao passo que a imigração per capita responde por $18,48 \%$.

O ordenamento das variáveis utilizado na análise da decomposição de variância foi dado pela ordem de Cholesky. 
Tabela 4 - Resultado da decomposição da variância do salário real (x)

\begin{tabular}{c|c|c|c|c} 
PERÍODO & \multicolumn{1}{c}{ S.E. } & \multicolumn{1}{c}{$\mathrm{x}$} & $\mathrm{z}$ \\
\hline 1 & 2,6023 & 2,74 & 97,26 & 0,00 \\
\hline 2 & 4,0651 & 24,54 & 75,44 & 0,02 \\
\hline 3 & 5,3672 & 47,95 & 52,02 & 0,03 \\
\hline 4 & 6,3054 & 56,93 & 42,01 & 1,06 \\
\hline 5 & 7,5814 & 69,29 & 29,85 & 0,85 \\
\hline 6 & 8,4806 & 64,99 & 27,53 & 7,47 \\
\hline 7 & 8,7571 & 61,16 & 26,46 & 12,38 \\
\hline 8 & 9,1063 & 57,24 & 24,49 & 18,26 \\
\hline 10 & 9,1168 & 57,17 & 24,45 & 18,38 \\
\hline & 9,1708 & 57,20 & 24,32 & 18,48 \\
\hline
\end{tabular}

Nota: "S.E" significa erro padrão.

Conforme a Tabela 5, os resultados da decomposição da variância dos erros de previsão da imigração per capita mostraram que, decorridos 10 anos após um choque não antecipado sobre essa variável, aproxima damente $51,98 \%$ de seu comportamento decorrem dela própria, sendo que os aproximadamente $48,02 \%$ são atribuídos à taxa de crescimento do PIB real per capita $(46,46 \%)$ e salário real $(1,56 \%)$.

Tabela 5 - Resultado da decomposição da variância da imigração per capita (z)

\begin{tabular}{c|c|c|c|c} 
PERÍODO & \multicolumn{1}{c}{ S.E. } & \multicolumn{1}{c}{$\mathrm{x}$} & $\mathrm{z}$ \\
\hline 1 & 0,0024 & 14,17 & 0,05 & 85,78 \\
\hline 2 & 0,0025 & 16,43 & 1,73 & 81,84 \\
\hline 3 & 0,0027 & 15,16 & 1,48 & 83,36 \\
\hline 4 & 0,0028 & 22,56 & 1,51 & 75,93 \\
\hline 5 & 0,0029 & 27,93 & 1,40 & 70,66 \\
\hline 6 & 0,0030 & 29,25 & 1,50 & 69,25 \\
\hline 7 & 0,0030 & 30,52 & 1,73 & 67,75 \\
\hline 8 & 0,0031 & 31,31 & 1,77 & 66,92 \\
\hline 9 & 0,0034 & 43,60 & 1,45 & 54,95 \\
\hline 10 & 0,0035 & 46,46 & 1,56 & 51,98 \\
\hline
\end{tabular}

Nota: "S.E" significa erro padrão. 
Em resumo, as evidências mostraram que os resultados da análise das funções de impulso-resposta e da decomposição da variância são condizentes com os resultados obtidos na análise de causalidade multivariada.

Entretanto, na estimação de VAR, impõe-se a restrição de que todas as equações tenham o mesmo número de defasagens em cada variável, o que pode afetar os resultados da análise de causalidade de Granger, que é sensível ao número de defasagens utilizadas. Por essa razão, a pró xima seção apresenta os resultados da análise de causalidade de Granger bivariada, realizada a partir da estimação de modelos ADL.

\subsection{Causalidade Bivariada}

Os resultados da análise de causalidade de Granger bivariada são reportados na Tabela 6. A taxa de crescimento do PIB real per capita Granger-causa unidirecionalmente a imigração per capita ao nível de significância de 5\%; em outras palavras, variações no crescimento econômico precederam temporalmente variações na imigração per capita. Esse resultado empírico confirma a análise de causalidade multivariada e oferece pouco suporte para a visão de que a imigração possuiu um importante efeito causal no crescimento econômico per capita no período da amostra. Ao contrário, esse resultado sugere que a expansão econô $\neg$ mica incentivou a imigração para o Brasil, inicialmente em virtude da expansão cafeeira no Estado de São Paulo, uma vez que as plantações de café prosperavam e necessitavam de mão-de-obra que substituísse o trabalho escravo.

A relação de causalidade de Granger unidirecional da taxa de cres $\neg$ cimento do PIB real per capita para o salário real, ao nível de significância de $10 \%$, sugere que o crescimento econômico é um previsor útil dos rendimentos do mercado de trabalho, confirmando os resultados encontrados na análise de causalidade multivariada.

Observa-se ausência de causalidade de Granger entre salários reais e imigração per capita, contrariando os resultados apresentados na análise multivariada. Os resultados da análise de causalidade multivariada su gerem que o impacto da imigração sobre os salários reais é indireto, através da terceira variável, a taxa de crescimento, isto é, desde que, na análise bivariada, o crescimento da economia causou ambos, a imigração 
e os salários, então era esse efeito indireto do crescimento na análise multivariada que induziu o resultado de que a imigração causou os salários reais.

Barbosa (2005) providenciou uma interpretação do efeito da imigra ção muito parecida, mas sem a vertente de causalidade. Argumentou-se, de um lado, que a mão-de-obra imigrante impactou o mercado de trabalho, uma vez que a quantidade demandada de trabalho era superior ao número de trabalhadores livres e escravos a partir de 1880. Apesar desse excesso da demanda, a mão-de-obra imigrante, maioria desquali $\neg$ ficada, recebia baixos salários e, dessa forma, não exerceu concorrência com os trabalhadores nacionais, pelo contrário, promoveu a obtenção de maiores lucros por parte dos empresários e fazendeiros brasileiros. A substituição da mão-de-obra escrava pela assalariada, em oferta crescen $\neg$ te, permitiu que se mantivesse a taxa de acumulação de capital nos níveis que propiciavam novos investimentos, em virtude da flexibilidade dos salários.

Tabela 6 - Resultado do teste de causalidade de Granger aplicado aos modelos ADL

\begin{tabular}{|c|c|c|c|c|c|}
\hline Hipótese Nula & Ons. & F & VALOR-P & Causa & $\mathrm{ADL}$ \\
\hline $\begin{array}{cc}x_{t} \text { não Granger-Causa } & y_{t} \\
y_{t} \text { não Granger-Causa } & x_{t}\end{array}$ & $\begin{array}{l}56 \\
54\end{array}$ & $\begin{array}{l}0,08 \\
2,18 \star \star \star\end{array}$ & $\begin{array}{l}0,7720 \\
0,0850\end{array}$ & $\begin{array}{l}\text { NÃO } \\
\text { SIM }\end{array}$ & $\begin{array}{l}\text { ADL }(2,1) \\
\text { ADL }(1,4)\end{array}$ \\
\hline $\begin{array}{l}z_{t} \text { não Granger-Causa } \\
y_{t} \text { não Granger-Causa } \\
z_{t}\end{array}$ & $\begin{array}{l}49 \\
49\end{array}$ & $\begin{array}{l}1,66 \\
2,14^{\star \star}\end{array}$ & $\begin{array}{l}0,1337 \\
0,0497\end{array}$ & $\begin{array}{l}\text { NÃO } \\
\text { SLM }\end{array}$ & $\begin{array}{l}\text { ADL }(2,9) \\
\text { ADL }(2,9)\end{array}$ \\
\hline $\begin{array}{l}z_{t} \text { não Granger-Causa } x_{t} \\
x_{t} \text { não Granger-Causa } z_{t}\end{array}$ & $\begin{array}{l}57 \\
56\end{array}$ & $\begin{array}{l}0,93 \\
0,42\end{array}$ & $\begin{array}{l}0,3379 \\
0,5182\end{array}$ & $\begin{array}{l}\text { NÃOO } \\
\text { NÃO }\end{array}$ & $\begin{array}{l}\text { ADL }(1,1) \\
\text { ADL }(2,1)\end{array}$ \\
\hline
\end{tabular}

Nota: ** - significância a 5\%; *** - significância a $10 \%$. Na escolha do número ótimo de defasagens, partiu-se de 10 defasagens. "Obs." é o $\mathrm{n}^{\circ}$. de observações.

\section{Conclusão}

Esse estudo investigou a natureza da relação de causalidade entre crescimento econômico, salário real e imigração no Brasil, segundo a abordagem de Granger (1969). Os resultados mostraram relação de causalidade unidirecional da taxa de crescimento do PIB real per capita para imigração per capita e para os salários reais. Esses resultados são robustos para as versões bivariada e multivariada, sugerindo que os 
imigrantes foram atraídos ao Brasil em virtude do crescimento econômico. Em outras palavras, mudanças na taxa de crescimento da renda real per capita sempre precederam mudanças nos níveis de imigração, de modo que é altamente provável que foi a expansão econômica que incentivou a imigração para o Brasil.

por outro lado, mudanças na taxa de crescimento do PIB real per capita Granger-causa o salário real, significando que variações no cres $\neg$ cimento econômico precederam temporalmente variações no salário real. Desde que a série de salário real era estacionária no período, a chegada dos imigrantes compensou os aumentos da demanda para tra balhadores, devido ao crescimento da economia, fazendo com que o equilíbrio no mercado de trabalho se mantivesse em um nível de salário real sem tendência.

No tocante à análise multivariada, os resultados das funções de impulso-resposta revelam que os efeitos de choques da força de trabalho imigrante e do salário real sobre a taxa de crescimento do PIB real per capita são poucos expressivos. Por outro lado, a imigração per capita e o salário real respondem a choques no crescimento econômico real de maneira significativa.

Além disso, os resultados para a análise de decomposição da variância mostraram que a taxa de crescimento do PIB real per capita é afetada principalmente pelo seu próprio comportamento $(72,89 \%)$. Por outro lado, pode-se notar que o salário real e a imigração per capita explicam o restante $27,11 \%$ da variância na taxa de crescimento do PIB real per capita. Além disso, observa-se que a taxa de crescimen $\neg$ to do PIB real per capita possui um maior poder explicativo para o salário real $(69,30 \%$ nos cinco primeiros anos e $57,20 \%$ no período subsequente) e para a imigração per capita $(27,93 \%$ nos 5 anos iniciais e $46,46 \%$ nos períodos restantes). Em outras palavras, o salário real e a imigração per capita estão mais subordinados às mudanças na taxa de crescimento do PIB real per capita. Os resultados apontam também para a insignificância do salário real na explicação da variância da imigração per capita (1,5\%), ao passo que a imigração per capita explica cerca de $18,5 \%$ das mudanças ocorridas no salário real.

Os resultados aqui encontrados corroboram as evidências obtidas por Morley (2006), em nações e períodos distintos aos deste estudo, de que a imigração foi determinada pelo crescimento econômico. 
Apêndice A: Trajetória das Séries de PIB Real per capita, Imigração per capita e Salário Real

Figura A.1 - Relaçâ entre taxa de crescimento do Plls real per capita (y) e imigraçào per apita (L)/

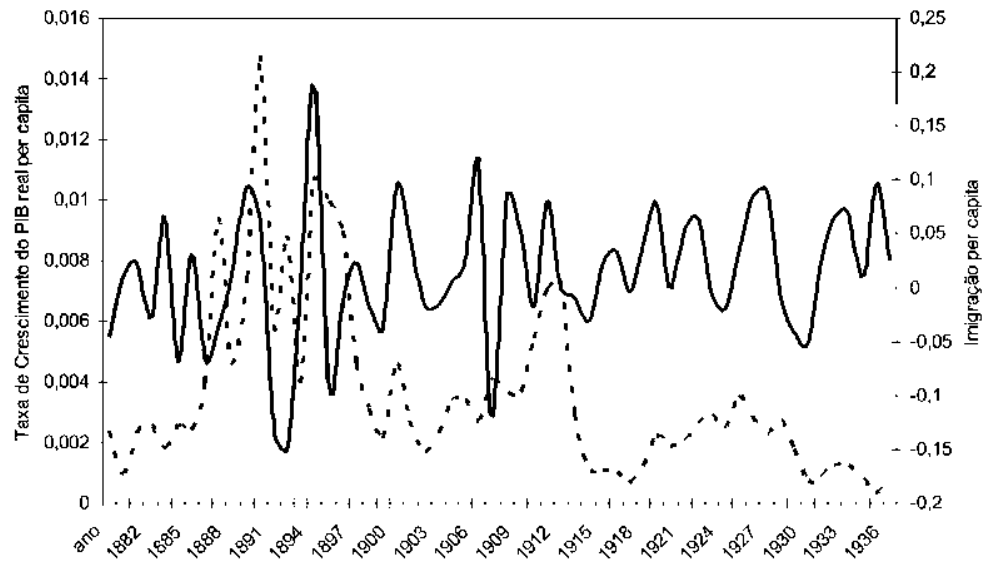

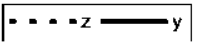

Figura A.2 - Relaça snere salário real (x) e imigrașào per capita (y)

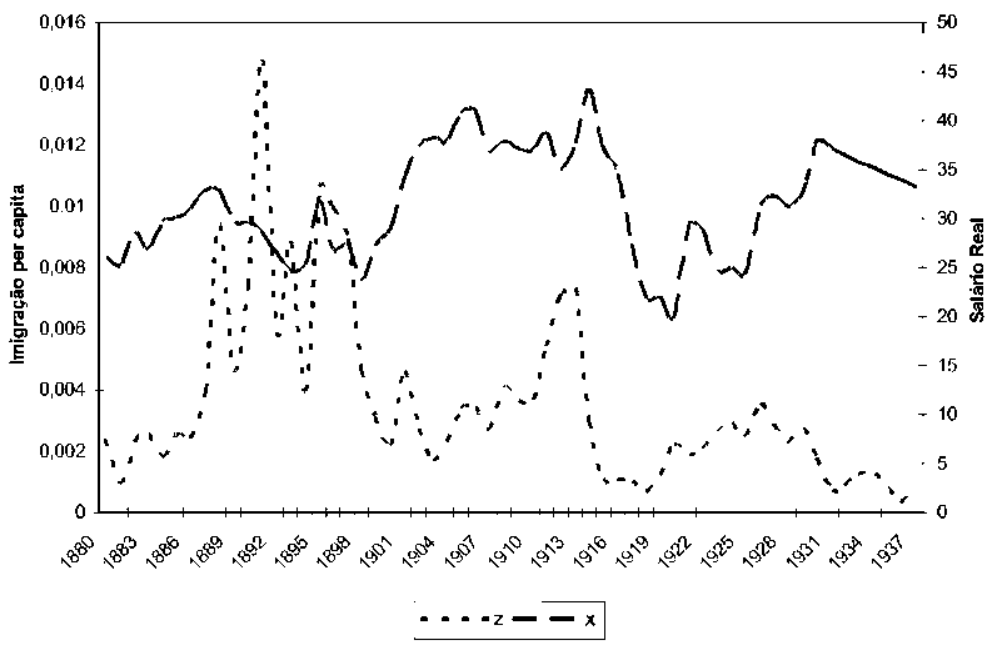


lïgura A.3 - Relacào entre salário real (x) e taxa de crescimento do PlB real perapita (y)

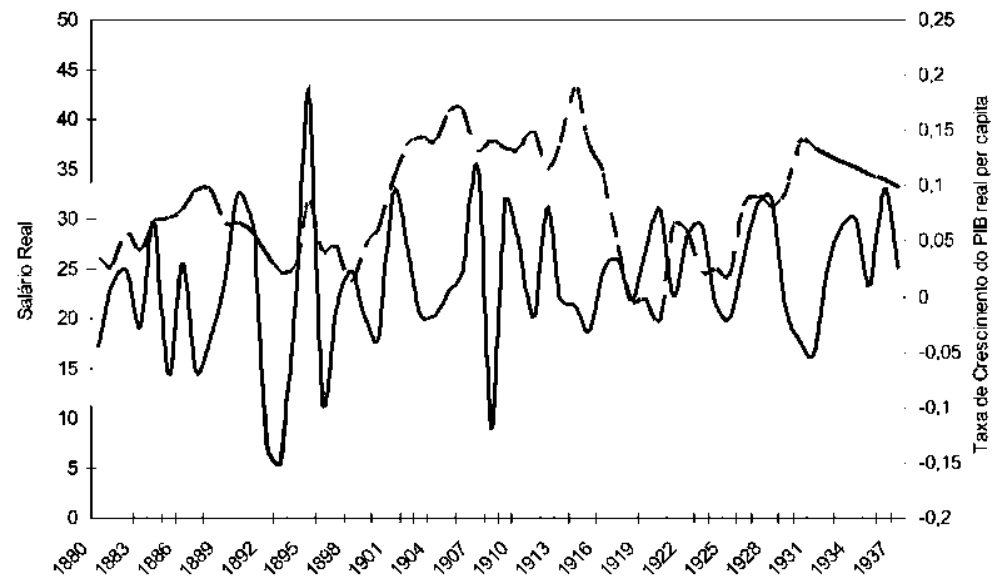

$\mid-\boldsymbol{x}-\mathrm{y}$

\section{Apêndice B: Dados Quantitativos de PIB Real per capita, Imigração per capita e Salário Real}

Tabela B.1 - PIB real per capita (1996 US\$): Brasil 1822 - 2000

\begin{tabular}{|c|c|c|c|c|c|c|c|c|c|c|c|}
\hline ANO & PIB & ANO & PIB & ANO & PIB & ANO & PIB & ANO & PIB & ANO & РIB \\
\hline & & 1851 & 578 & 1881 & 629 & 1911 & 641 & 1941 & 1.275 & 1971 & 3.905 \\
\hline 1822 & 452 & 1852 & 531 & 1882 & 644 & 1912 & 693 & 1942 & 1.212 & 1972 & 4.256 \\
\hline 1823 & 433 & 1853 & 498 & 1883 & 626 & 1913 & 691 & 1943 & 1.284 & 1973 & 4.703 \\
\hline 1824 & 439 & 1854 & 481 & 1884 & 668 & 1914 & 685 & 1944 & 1.350 & 1974 & 4.983 \\
\hline 1825 & 424 & 1855 & 485 & 1885 & 621 & 1915 & 664 & 1945 & 1.359 & 1975 & 5.082 \\
\hline 1826 & 385 & 1856 & 503 & 1886 & 641 & 1916 & 678 & 1946 & 1.455 & 1976 & 5.501 \\
\hline 1827 & 437 & 1857 & 538 & 1887 & 598 & 1917 & 701 & 1947 & 1.458 & 1977 & 5.647 \\
\hline 1828 & 464 & 1858 & 573 & 1888 & 576 & 1918 & 698 & 1948 & 1.525 & 1978 & 5.688 \\
\hline 1829 & 572 & 1859 & 568 & 1889 & 583 & 1919 & 725 & 1949 & 1.592 & 1979 & 5.968 \\
\hline 1830 & 591 & 1860 & 583 & 1890 & 638 & 1920 & 782 & 1950 & 1.656 & 1980 & 6.327 \\
\hline 1831 & 551 & 1861 & 578 & 1891 & 678 & 1921 & 781 & 1951 & 1.688 & 1981 & 5.961 \\
\hline 1832 & 418 & 1862 & 551 & 1892 & 588 & 1922 & 825 & 1952 & 1.786 & 1982 & 5.917 \\
\hline 1833 & 694 & 1863 & 563 & 1893 & 500 & 1923 & 878 & 1953 & 1.847 & 1983 & 5.674 \\
\hline 1834 & 524 & 1864 & 571 & 1894 & 500 & 1924 & 872 & 1954 & 1.912 & 1984 & 5.855 \\
\hline 1835 & 453 & 1865 & 614 & 1895 & 593 & 1925 & 855 & 1955 & 1.975 & 1985 & 6.158 \\
\hline
\end{tabular}




\begin{tabular}{l|l|l|l|l|l|l|l|l|l|l|l}
\hline 1836 & 518 & 1866 & 636 & 1896 & 538 & 1926 & 882 & 1956 & 1.999 & 1986 & 6.469 \\
\hline 1837 & 705 & 1867 & 689 & 1897 & 531 & 1927 & 957 & 1957 & 2.132 & 1987 & 6.585 \\
\hline 1838 & 677 & 1868 & 689 & 1898 & 543 & 1928 & 1.043 & 1958 & 2.197 & 1988 & 6.469 \\
\hline 1839 & 654 & 1869 & 689 & 1899 & 533 & 1929 & 1.034 & 1959 & 2.307 & 1989 & 6.571 \\
\hline 1840 & 658 & 1870 & 638 & 1900 & 513 & 1930 & 992 & 1960 & 2.395 & 1990 & 6.212 \\
\hline 1841 & 634 & 1871 & 638 & 1901 & 561 & 1931 & 941 & 1961 & 2.631 & 1991 & 6.222 \\
\hline 1842 & 641 & 1872 & 661 & 1902 & 588 & 1932 & 963 & 1962 & 2.676 & 1992 & 6.073 \\
\hline 1843 & 609 & 1873 & 641 & 1903 & 578 & 1933 & 1.025 & 1963 & 2.754 & 1993 & 6.294 \\
\hline 1844 & 637 & 1874 & 651 & 1904 & 568 & 1934 & 1.097 & 1964 & 2.769 & 1994 & 6.575 \\
\hline 1845 & 629 & 1875 & 661 & 1905 & 571 & 1935 & 1.108 & 1965 & 2.841 & 1995 & 6.766 \\
\hline 1846 & 591 & 1876 & 636 & 1906 & 583 & 1936 & 1.216 & 1966 & 2.876 & 1996 & 6.881 \\
\hline 1847 & 614 & 1877 & 618 & 1907 & 651 & 1937 & 1.247 & 1967 & 2.964 & 1997 & 7.014 \\
\hline 1848 & 605 & 1878 & 648 & 1908 & 573 & 1938 & 1.309 & 1968 & 3.201 & 1998 & 6.733 \\
\hline 1849 & 562 & 1879 & 653 & 1909 & 621 & 1939 & 1.281 & 1969 & 3.353 & 1999 & 6.885 \\
\hline 1850 & 511 & 1880 & 623 & 1910 & 653 & 1940 & 1.243 & 1970 & 3.600 & 2000 & 7.185 \\
\hline
\end{tabular}

Fonte: De Castro e Gonçalves (2003), disponível em <www.unb.br/face/eco/steve >. Acessado em $30 / 10 / 2008$

A série foi construída a partir das seguintes fontes:

1950-2000: as tabelas do Summers-Heston em dólares (US\$) de 1996, corrigidos pela paridade de poder de compra (PPC), disponível no: <http://pwt.econ.upenn.edu/>. Acessado em 30/10/2008

1850-1950: os índices de Goldsmith (1986), representando o PIB real per capita em moeda nacional, foram aplicados para continuar a série em dólares, usando-se a justificativa de Heston e Summers (1980).

1822-1849: estimativa pelos autores, a partir dos dados monetários, e a metodologia apresentados em Leff (1972). Como foi indicado pelos autores, a série resultante nesse período subestima o PIB real per capita, porque não tomou conta da suposta estagnação da renda não monetizada dos agentes nos setores de subsistência. Quer dizer, as taxas usadas para as interpolações para trás eram superestimadas.

Tabela B.2 - Taxa de Crescimento do PIB real per capita: Brasil 1870 — 1937

\begin{tabular}{c|c|c|c}
\hline \multicolumn{1}{c}{ PERÍODO } & \multicolumn{1}{c}{ SÉRIE } & PERÍODO & \multicolumn{1}{c}{ SÉRIE } \\
\hline 1880 & $-0,045942$ & 1909 & 0,083770 \\
\hline 1881 & 0,009631 & 1910 & 0,051530 \\
\hline 1882 & 0,023847 & 1911 & $-0,018377$ \\
\hline 1883 & $-0,027950$ & 1912 & 0,081123 \\
\hline 1884 & 0,067093 & 1913 & $-0,002886$ \\
\hline 1885 & $-0,070359$ & 1914 & $-0,008683$ \\
\hline 1886 & 0,032206 & 1915 & $-0,030657$ \\
\hline
\end{tabular}




\begin{tabular}{|c|c|c|c|}
\hline 1887 & $-0,067083$ & 1916 & 0,021084 \\
\hline 1888 & $-0,036789$ & 1917 & 0,033923 \\
\hline 1889 & 0,012153 & 1918 & $-0,004280$ \\
\hline 1890 & 0,094340 & 1919 & 0,038682 \\
\hline 1891 & 0,062696 & 1920 & 0,078621 \\
\hline 1892 & $-0,132743$ & 1921 & $-0,001279$ \\
\hline 1893 & $-0,149660$ & 1922 & 0,056338 \\
\hline 1894 & 0,000000 & 1923 & 0,064242 \\
\hline 1895 & 0,186000 & 1924 & $-0,006834$ \\
\hline 1896 & $-0,092749$ & 1925 & $-0,019495$ \\
\hline 1897 & $-0,013011$ & 1926 & 0,031579 \\
\hline 1898 & 0,022599 & 1927 & 0,085034 \\
\hline 1899 & $-0,018416$ & 1928 & 0,089864 \\
\hline 1900 & $-0,037523$ & 1929 & $-0,008629$ \\
\hline 1901 & 0,093567 & 1930 & $-0,040619$ \\
\hline 1902 & 0,048128 & 1931 & $-0,051411$ \\
\hline 1903 & $-0,017007$ & 1932 & 0,023379 \\
\hline 1904 & $-0,017301$ & 1933 & 0,064382 \\
\hline 1905 & 0,005282 & 1934 & 0,070244 \\
\hline 1906 & 0,021016 & 1935 & 0,010027 \\
\hline 1907 & 0,116638 & 1936 & 0,097473 \\
\hline 1908 & $-0,119816$ & 1937 & 0,025493 \\
\hline
\end{tabular}

Nota: elaboração do autor. As taxas são por 1 e não por 100 (por cento, \%).

Tabela B.3 - Entrada anual de Imigrantes, Residentes e Imigração per capita: Brasil 18701937

\begin{tabular}{|c|c|c|c|c|c|c|c|}
\hline PERÍODO & ENTRADA & POPULAÇÃO & IMIGRAÇÃO & PERÍODO & ENTRADA & POPULAÇÃO & IMIGRAÇÃO \\
\hline & IMIGRANTES & DE RESIDENTES & PER CAPITA & & IMIGRANTES & DE RESIDENTES & PER CAPITA \\
\hline 1870 & 5.158 & 9.797 .000 & 0,00052649 & 1904 & 44.706 & 19.662 .618 & 0,002273655 \\
\hline 1871 & 12.431 & 9.947 .000 & 0,00124972 & 1905 & 68.488 & 20.299 .476 & 0,00337388 \\
\hline 1872 & 19.219 & 10.099 .000 & 0,00190306 & 1906 & 72.332 & 20.960 .919 & 0,003450803 \\
\hline 1873 & 14.742 & 10.372 .096 & 0,00142131 & 1907 & 57.919 & 21.643 .078 & 0,002676098 \\
\hline 1874 & 20.332 & 10.774 .021 & 0,00188713 & 1908 & 90.536 & 22.342 .083 & 0,004052263 \\
\hline 1875 & 14.590 & 11.139 .349 & 0,00130977 & 1909 & 84.090 & 23.054 .064 & 0,003647513 \\
\hline 1876 & 30.747 & 11.471 .179 & 0,00268037 & 1910 & 86.751 & 23.775 .153 & 0,003648809 \\
\hline
\end{tabular}




\begin{tabular}{|c|c|c|c|c|c|c|c|}
\hline 1877 & 29.468 & 11.772 .608 & 0,0025031 & 1911 & 133.575 & 24.501 .479 & 0,005451712 \\
\hline 1878 & 24.456 & 12.046 .732 & 0,00203009 & 1912 & 177.887 & 25.229 .172 & 0,007050846 \\
\hline 1879 & 22.788 & 12.296 .650 & 0,00185319 & 1913 & 190.343 & 25.954 .364 & 0,007333757 \\
\hline 1880 & 30.355 & 12.525 .458 & 0,00242346 & 1914 & 79.232 & 26.673 .184 & 0,002970474 \\
\hline 1881 & 11.548 & 12.736 .253 & 0,0009067 & 1915 & 30.333 & 27.381 .763 & 0,001107781 \\
\hline 1882 & 29.589 & 12.932 .134 & 0,00228802 & 1916 & 31.245 & 28.076 .232 & 0,001112863 \\
\hline 1883 & 34.015 & 13.116 .197 & 0,00259336 & 1917 & 30.277 & 28.752 .720 & 0,001053013 \\
\hline 1884 & 23.574 & 13.291 .540 & 0,00177361 & 1918 & 19.793 & 29.407 .358 & 0,000673063 \\
\hline 1885 & 34.724 & 13.461 .259 & 0,00257955 & 1919 & 36.027 & 30.036 .276 & 0,00119945 \\
\hline 1886 & 32.650 & 13.628 .453 & 0,00239572 & 1920 & 69.041 & 30.635 .605 & 0,00225362 \\
\hline 1887 & 54.932 & 13.796 .218 & 0,00398167 & 1921 & 58.476 & 31.202 .824 & 0,001874061 \\
\hline 1888 & 132.070 & 13.967 .652 & 0,00945542 & 1922 & 65.007 & 31.740 .804 & 0,002048058 \\
\hline 1889 & 65.165 & 14.145 .852 & 0,00460665 & 1923 & 84.549 & 32.253 .767 & 0,002621368 \\
\hline 1890 & 106.819 & 14.333 .915 & 0,00745219 & 1924 & 96.052 & 32.745 .933 & 0,00293325 \\
\hline 1891 & 215.239 & 14.534 .939 & 0,01480839 & 1925 & 82.547 & 33.221 .524 & 0,002484745 \\
\hline 1892 & 85.906 & 14.752 .021 & 0,00582334 & 1926 & 118.686 & 33.684 .758 & 0,003523433 \\
\hline 1893 & 132.589 & 14.988 .258 & 0,00884619 & 1927 & 97.974 & 34.139 .858 & 0,002869783 \\
\hline 1894 & 60.182 & 15.246 .747 & 0,0039472 & 1928 & 78.128 & 34.591 .044 & 0,002258619 \\
\hline 1895 & 164.831 & 15.530 .586 & 0,01061331 & 1929 & 96.186 & 35.042 .537 & 0,002744836 \\
\hline 1896 & 157.423 & 15.842 .872 & 0,00993652 & 1930 & 62.610 & 35.498 .557 & 0,001763734 \\
\hline 1897 & 144.866 & 16.186 .703 & 0,00894969 & 1931 & 27.465 & 35.963 .325 & 0,000763695 \\
\hline 1898 & 76.862 & 16.565 .175 & 0,00463998 & 1932 & 31.494 & 36.441 .062 & 0,000864245 \\
\hline 1899 & 53.610 & 16.981 .387 & 0,00315699 & 1933 & 46.081 & 36.935 .989 & 0,001247591 \\
\hline 1900 & 37.807 & 17.438 .434 & 0,00216803 & 1934 & 46.027 & 37.452 .325 & 0,001228949 \\
\hline 1901 & 83.116 & 17.938 .254 & 0,00463345 & 1935 & 29.585 & 37.994 .292 & 0,00077867 \\
\hline 1902 & 50.472 & 18.478 .137 & 0,00273144 & 1936 & 12.773 & 38.566 .111 & 0,000331198 \\
\hline 1903 & 32.941 & 19.054 .215 & 0,0017288 & 1937 & 34.677 & 39.172 .002 & 0,00088525 \\
\hline
\end{tabular}

Fonte: População de residentes - 1870-1872: Leff (1991). 1873-1937: Instituto de Pesquisa Econômica Aplicada (Ipea). Entrada de imigrantes - 1870-1937: os dados foram obtidos no sitio eletrônico do Ipea, tendo como fonte original o Departamento Nacional de Imigração e o Instituto Nacional de Imigração e Colonização. Tabela extraída de: Anuário Estatístico do Brasil 1960. Rio de Janeiro: IBGE, vol. 21, 1960. 
Tabela B.4 - Salário Real Ajustado pela Paridade do Poder de Compra. Grã-Bretanha, $1913=100$

\begin{tabular}{|c|c|c|c|c|c|}
\hline ANO & $\begin{array}{c}\text { BRASIL, } \\
\text { SUDESTE }\end{array}$ & ANO & $\begin{array}{l}\text { BRASIL, } \\
\text { SUDESTE }\end{array}$ & ANO & $\begin{array}{c}\text { BRASIL, } \\
\text { SUDESTE }\end{array}$ \\
\hline 1830 & 16,0 & 1870 & 16,8 & 1910 & 37,0 \\
\hline 1831 & 15,7 & 1871 & 20,3 & 1911 & 38,7 \\
\hline 1832 & 20,9 & 1872 & 19,9 & 1912 & 35,0 \\
\hline 1833 & 9,3 & 1873 & 21,8 & 1913 & 37,6 \\
\hline 1834 & 9,3 & 1874 & 20,5 & 1914 & 43,3 \\
\hline 1835 & 13,9 & 1875 & 25,1 & 1915 & 37,3 \\
\hline 1836 & 14,2 & 1876 & 24,9 & 1916 & 34,6 \\
\hline 1837 & 13,1 & 1877 & 24,0 & 1917 & 27,5 \\
\hline 1838 & 11,3 & 1878 & 22,8 & 1918 & 21,8 \\
\hline 1839 & 12,2 & 1879 & 25,3 & 1919 & 21,9 \\
\hline 1840 & 9,7 & 1880 & 26,1 & 1920 & 19,9 \\
\hline 1841 & 10,4 & 1881 & 25,1 & 1921 & 29,5 \\
\hline 1842 & 15,6 & 1882 & 28,5 & 1922 & 28,8 \\
\hline 1843 & 15,4 & 1883 & 26,8 & 1923 & 24,6 \\
\hline 1844 & 16,1 & 1884 & 29,6 & 1924 & 25,0 \\
\hline 1845 & 13,1 & 1885 & 30,2 & 1925 & 24,2 \\
\hline 1846 & 12,1 & 1886 & 30,9 & 1926 & 31,2 \\
\hline 1847 & 13,7 & 1887 & 32,8 & 1927 & 32,4 \\
\hline 1848 & 13,3 & 1888 & 32,9 & 1928 & 31,3 \\
\hline 1849 & 15,8 & 1889 & 29,6 & 1929 & 32,5 \\
\hline 1850 & 18,0 & 1890 & 29,6 & 1930 & 37,8 \\
\hline 1851 & 15,9 & 1891 & 28,6 & 1931 & 37,1 \\
\hline 1852 & 17,2 & 1892 & 26,5 & 1932 & 36,5 \\
\hline 1853 & 20,0 & 1893 & 24,7 & 1933 & 35,8 \\
\hline 1854 & 15,3 & 1894 & 25,1 & 1934 & 35,2 \\
\hline 1855 & 15,2 & 1895 & 31,7 & 1935 & 34,5 \\
\hline 1856 & 15,9 & 1896 & 26,8 & 1936 & 33,9 \\
\hline 1857 & 15,8 & 1897 & 27,4 & 1937 & 33,3 \\
\hline 1858 & 18,0 & 1898 & 23,6 & & \\
\hline 1859 & 18,2 & 1899 & 27,2 & & \\
\hline 1860 & 20,9 & 1900 & 29,0 & & \\
\hline
\end{tabular}




\begin{tabular}{l|l|l|l|l|l}
\hline 1861 & 20,9 & 1901 & 34,0 & & \\
\hline 1862 & 20,5 & 1902 & 37,4 & & \\
\hline 1863 & 19,1 & 1903 & 38,3 & & \\
\hline 1864 & 17,9 & 1904 & 37,9 & & \\
\hline 1865 & 18,6 & 1905 & 40,8 & & \\
\hline 1866 & 18,8 & 1906 & 40,9 & & \\
\hline 1867 & 20,7 & 1907 & 36,8 & & \\
\hline 1868 & 19,4 & 1908 & 37,9 & & \\
\hline 1869 & 16,5 & 1909 & 37,2 & & \\
\hline
\end{tabular}

Fonte: Williamson (1998), apêndice, tabela 7.2; Disponível em: <http://www.economics.harvard. edu/faculty/williamson/jwilliamworkingpapers $>$. Acessado em 30/10/2008.

Bertóla et al. (1999) apresenta benchmarks de salário real, ajustado pela paridade do poder de compra para Argentina, Uruguai e Sudeste do Brasil, com relação à Grã-Bretanha. Williamson (1998) utilizou os dados de Bertóla et al. (1999) para construir seu benchmark de salário real, utilizando-se também os dados constantes em Williamson's Atlantic Economy Real Wage Data (1995), revistos em O'Rourke e Williamson (1997), para construir as séries de salários reais ajustados para Argentina, Uruguai e Sudeste do Brasil, com relação à Grã-Bretanha $(1913=100)$. Para maiores detalhes, ver Williamson (1998), Apêndice Tabela 7.2, página 33.

\section{Referências bibliográficas}

ABRAMOVITZ, M."The nature and significance of Kuznets cycles". Economic Development and Cultural Change, v. 9, 1961: 225-248.

BÉRtolA, L; CAMOU, M. \& PORCILE, G. Comparación International del Poder Adquisitivo de los Salarios Reales de los Paises del Cono Sur, 1870-1945. Artigo apresentado no simpósio "Mercado del Trabajo y Nivel de Vida" das "Segundas Jornadas de Histo ria Económica", Montevideo, Julho 1999.

BARBOSA, F. B. C. "Contribuições da economia algodoeira e cafeeira ao desenvolvimento do Maranhão e de São Paulo". Cadernos de Ciência e Tecnologia, Brasília, v. 22, n. 3, set./dez. 2005: 587-611.

BORJAS, G. J. "The economics of immigration".Journal of Economic Literature, 32, 1994: 1667-1717.

COLLINS, W J.; O'ROURKE, K. H. \& WILLIAMSON, J. G. "Were trade and factor mobility substitutes in history?" National Bureau of Economic Research Working Paper 6059, June 1997.

DEAN,W. Industrialização de São Paulo, 1880-1945. 4" edição, São Paulo: Bertrand Brasil, 1991.

DE CASTRO, S. \& GONÇALVES, F. "A test for mixed Poisson growth in Brazils GDP per person, 1822-2000, and an estimate of the world's mixing distribution in 1800". 
Anais do XX V Encontro Brasileiro de Econometria, vol. 1, 2003: 393-409; disponível em: 〈www.unb.br/face/eco/steve $\rangle$. Acessado em 30/10/2008.

DICKEY, D. A. \& FULLER, W. A. "Distribution of the estimators for autoregressive time series with unit root". Journal of the American Statistical Association, 74, 1979.

"Likelihood ratio statistics for auto-regressive time series with unit root". Econometrica, 49, n. 4, 1981.

ELLIOT, G., ROTHEMBERG, T. J. \& STOCK, J. H. "Efficient tests for an autoregressive unit root". Econometrica 64 (4), 1996: 813-836.

ENDERS,W. Applied econometric time series. 2. Ed.Wiley Series in Probability and Statistics. Nova York: International Edition - Wiley, 2004.

FERIDUN, M. "Does immigration have an impact on economic development and unemployment? Empirical evidence from Finland (1981-2001)". International Journal of Applied Econometrics and Quantitative Studies, v. 1-3, 2004.

FRIEDBERG, R. \& HUNT, J. "The impact of immigrants on host country wages, employment and growth". The Journal of Economic Perspectives, v. 9, n. 2, 1995: 23-44.

GRAHAM, D. H. "Migração estrangeira e a questão da oferta de mão-de-obra no crescimento econômico brasileiro: 1880-1930". Estudos Econômicos, v. 3, n.1, 1973: 38-44.

GRANGER, C. W J. "Investigating causal relations by econometric models and crossspectral models". Econometrica, 34, 1969: 541-551.

GOLDSMITH, R. W. "Brasil 1850-1984: Desenvolvimento financeiro sob um século de inflação". Editora Harper e Row do Brasil Ltda. 1986.

HESTON, A. \& SUMMERS, R. "Comparative Indian economic growth: 1870 to 1970". American Economic Review, 70 (2), 1980: 96-101.

HOLlOWAY, T. H. "Condições do mercado de trabalho e organização do trabalho nas plantações e na economia cafeeira de São Paulo. 1885-1915 - uma análise preliminar". Estudos Econômicos. São Paulo, v. 2, n. 6, dez. 1972.

KUZNETS, S. Secular movements in production and prices. New York: National Bureau of Economic Research, 1930.

LEFF N. H. "A technique for estimating income trends from currency data and an ap plication to nineteenth-century Brazil". Review of Income and Wealth 18(4), 1972: 335-368.

Subdesenvolvimento e desenvolvimento no Brasil - Volume I. Rio de Janeiro: Expressão e Cultura, 1991.

LEVY, M. S. F. "O papel da migração internacional na evolução da população brasileira (1872 a 1972)". Revista Saúde Pública, v. 8, 1974: 49-90.

MORLEY, B. "Causality between economic growth and immigration: an ARDL bounds testing approach". Economics Letters, 90, 2006: 72-76.

NG, S. \& PERRON, P. "Lag length selection and the construction of unit root tests with good size and power". Econometrica, 69, 6, 2001.

O'ROURKE, K. \& WILLIAMSON, J. G. "Around the European periphery 1870-1913: globalization, schooling and growth". European Review of Economic History, 1(2), August 1997: 153-90. 
PHILLIPS, P.C. B. "Ti me series regression with unit roots. Econometrica, 55, 1987:277-302.

PHILLIPS, P. C. B. \& PERRON, P. "Testing for unit root in time series regression". Biometrika, 75, 1988: 335-346.

SAID, S. \& DICKEY, D. A. "Testing for unit roots in autoregressive-moving average models of unknown order". Biometrika, 71, 1984.

STOLKE, V \& HALL, M. M. "The introduction of free labour into São Paulo coffee plantations".Journal of Peasant Studies, v. 10, n. 2-3, 1983: 170-200.

SOLIMANO, A. "Development cycles, political regimes and international migration: Argentina in the twentieth century". CEPAL - Serie Macroeconomia del desarrollo, n. 22, 2003.

WILliAMSON, J. "Migration to the New World: long term influences and impact". Explorations in Economic History, v. 11 (4), 1974: 357-390.

"Real Wages and Relative Factor Prices in the Third World 1820-1940: Latin America". Harvard Institute of Economic Research Discussion Paper Number 1853, November 1998, Disponível em: <http://www.economics.harvard.edu/faculty/willia mson/jwilliamworkingpapers >. Acessado em 30/10/2008. 